\title{
Brown Rice Extract Ameliorates Oxidative Status in Human Placental Cell Line (JEG-3) Induced by Cadmium Chloride
}

\section{Tantip BOONSONG* and Wajathip BULANAWICHIT}

Department of Biochemistry, Faculty of Medical Science, Naresuan University, Phitsanulok 65000, Thailand

('Corresponding author's e-mail: tantips@hotmail.com, tantipb@nu.ac.th)

Received: 4 July, 2018, Revised: 7 February, 2019, Accepted: 10 March 2019

\begin{abstract}
Cadmium (Cd) can induce oxidative stress by producing reactive oxygen species (ROS) and affect the antioxidant defense systems, leading to cellular damage. Supplementation with antioxidants may protect against $\mathrm{Cd}$-induced oxidative stress. This study aimed to investigate the effect of germinated brown rice $(\mathrm{GBR})$, brown rice $(\mathrm{BR})$, and white rice (WR) extracts against Cd-induced toxicity in human placenta (JEG-3) cells. The cytotoxicity of $\mathrm{Cd}$ and rice extracts was measured by MTT assay, and pretreatments with GBR, BR, and WR before Cd exposure were examined. Intracellular ROS levels and the expression of SOD2 and GPx4 were determined by DCFH-DA assay and western blot, respectively. An antioxidant N-acetylcysteine (NAC) was used as a positive control. The antioxidant capacity and total phenolic content of rice extracts were investigated by DPPH and Folin-Ciocalteu methods, respectively. The GBR extract exhibited the highest antioxidant activity and total phenolic content, followed by BR and WR, respectively. Cd decreased cell viability in a dose-dependent manner, whereas incubation with $0.1-0.5 \mathrm{mg} / \mathrm{mL}$ showed no toxicity in all rice extracts. Moreover, Cd treatments significantly $(p<0.05)$ increased ROS levels. Conversely, treatments with GBR and BR extracts decreased ROS. Similar results were observed for combinatorial treatments of GBR and BR with $\mathrm{Cd}$, except for WR treatment. Additionally, significant increased SOD2 and decreased GPx4 expression levels were evident in the GBR group and in both GBR and BR pre-treated groups, respectively, compared to Cd exposure alone. These results suggest that brown rice pre-treatments may ameliorate oxidative status induced by $\mathrm{Cd}$ in cultured human placental cells.
\end{abstract}

Keywords: Cadmium, JEG-3, Brown rice, Oxidative status, Antioxidant

\section{Introduction}

Cadmium (Cd), a toxic metal ion, has been known as a high risk for health problems, through either acute or long-term exposure. Cd can be found in all areas, including air, water, soil, tobacco, and food [1] inducing toxicity in various organs, such as the liver, kidneys, lungs, and gastrointestinal tract, and the reproductive, respiratory, and skeletal systems [2-5]. Cd can induce abnormalities in the fetus when administered during gestation. In pregnant rats, feeding with $\mathrm{Cd}$ caused organ malformations of the fetus [6]. In humans, during pregnancy, cadmium exposure via the environment and/or cigarette smoking leads to fetal growth restriction [7] and human infertility [8] and induces spontaneous abortion [9].

It is known that $\mathrm{Cd}$ induces oxidative stress by producing reactive oxygen species (ROS) [10,11], such as superoxide anion $\left(\mathrm{O}^{\bullet}{ }^{\bullet}\right)$, hydrogen peroxide $\left(\mathrm{H}_{2} \mathrm{O}_{2}\right)$, and hydroxyl radicals $\left(\mathrm{HO}^{\bullet}\right)$, and affects the antioxidant defense systems, leading to cellular damage by enhancing lipid peroxidation, protein oxidation, and oxidized DNA [12]. 
Within the cells, antioxidants play a vital role to protect cells against the adverse effects of free radicals. These antioxidants include enzymatic antioxidants [superoxide dismutase (SOD), catalase (CAT), and glutathione peroxidase (GPx)] and non-enzymatic antioxidants [glutathione, uric acid, and bilirubin]. In addition, dietary antioxidants can also contribute to cellular protection against ROS, such as vitamin $\mathrm{E}$, vitamin $\mathrm{C}$, carotenoids, and flavonoids [13].

A previous study [14] demonstrated that vitamin E supplements in rats reduced lipid peroxidation and hemolysis of red blood cells due to oxidative damage induced by cadmium chloride $\left(\mathrm{CdCl}_{2}\right)$. Another recent study [15] in pregnant rats revealed that vitamin $\mathrm{E}$ and wheat germ oil supplements can eliminate the toxic effects of $\mathrm{Cd}$ via increasing antioxidant enzyme activities in both mothers and fetuses, when compared treatment with $\mathrm{Cd}$ only. This suggests that antioxidants can exert a protective role against $\mathrm{Cd}-$ induced oxidative stress.

Rice (Oryza sativa L.) is a staple food worldwide, especially in Asian countries. Polished rice or white rice (WR) seeds are widely consumed but, at present, brown rice (BR) is popular because of its high nutrition [16]. The outer layer parts of BR grains or rice bran contain beneficial nutritives, but most of these parts are removed during the milling process. One of the major bioactive components in BR is $\gamma-$ oryzanol, a mixture of ferulate esters and plant sterols [17], and these components are intensely increased in germinated brown rice (GBR) during the germination process [18]. $\gamma$-Oryzanol has important biological properties, including cholesterol-lowering [19], anti-inflammatory [20], anticancer [21], antidiabetic [22], and antioxidant activities [23].

The aim of this study was to investigate a possible protective effect of brown rice, germinated brown rice, and white extracts on the antioxidant defense system in human placenta JEG-3 cells treated with Cd. NAC was used as an antioxidant standard. The selected biochemical parameters were intracellular ROS and expressions of antioxidant proteins, SOD2 and GPx4.

\section{Materials and methods}

\section{Cell culture}

JEG-3 cells (HTB-36; ATCC, Rockville, USA) were cultured in Eagle's minimal essential medium (MEM) (Corning, USA), containing $10 \%$ fetal bovine serum (Gibco, USA) and antibiotics (Gibco, USA) at $37{ }^{\circ} \mathrm{C}$ in a humidified atmosphere of $5 \% \mathrm{CO}_{2}$ and $95 \%$ air. The study was approved by Naresuan University Institutional Review Board (IRB. No.297/58).

\section{Rice extracts preparation}

Thai brown rice (Khao Dawk Mali105; KDML105) was obtained from Lopburi Rice Research Center, Thailand. The germination method was modified from Patil and Khan [24]. Briefly, $100 \mathrm{~g}$ of BR was soaked in $200 \mathrm{~mL}$ of sterile water at room temperature for $6 \mathrm{~h}$ and germinated for $24 \mathrm{~h}$. The extraction process was modified from a previous study [25]. Firstly, the WR, BR, and GBR were ground into powder and extracted twice in $70 \%(\mathrm{v} / \mathrm{v})$ methanol solution. Then, the mixture was shaken for $20 \mathrm{~h}$ at $37{ }^{\circ} \mathrm{C}$, filtered, and evaporated by rotary evaporation (BUCHI, Switzerland). The crude rice extracts were weighed and dissolved in dimethyl sulfoxide (DMSO) (final concentration $0.1 \%$ ) as the stock solution.

\section{Determination of cell viability}

Cells were grown at a density of $2 \times 10^{3}$ cells/well in a 96-well plate and treated with various concentrations of $\mathrm{CdCl}_{2}$ and rice extracts (WR, BR, and GBR) for 24 and $48 \mathrm{~h}$, respectively. Culture supernatants were then removed and replaced by $180 \mu \mathrm{l}$ of fresh free-serum medium. Following this, 20 $\mu \mathrm{l}$ of MTT solution $(5 \mathrm{mg} / \mathrm{mL})$ was added into each well. After $2 \mathrm{~h}$, the unreacted reagent was removed, the insoluble formazan crystals were dissolved in DMSO (100 $\mu \mathrm{l} /$ well), and absorbance at $595 \mathrm{~nm}$ was measured using a microplate reader (Biotek, USA). The cell viability was determined as percentage over control. 


\section{Assessment of intracellular ROS levels}

To study the effects of $\mathrm{Cd}$ and 3 rice (WR, BR, and GBR) samples on ROS levels, the 2', 7'dichlorofluoroscein diacetate (DCFH-DA) was used. Briefly, cells were divided into 3 treatment groups. In the first 2 groups, cells were treated with $\mathrm{Cd}$ and rice samples for $24 \mathrm{~h}$ and $48 \mathrm{~h}$, respectively. For the third group, cells were pre-treated with WR, BR and GBR extracts for $48 \mathrm{~h}$, followed by $24 \mathrm{~h} \mathrm{Cd}$ exposure. For a positive control group, cells were pre-treated with N-acetylcysteine (NAC) for $48 \mathrm{~h}$. After treatments, cells were then washed with $0.1 \mathrm{~mL}$ of PBS per well. Following this, $100 \mu \mathrm{M}$ DCFH-DA was added and the cells were incubated for $30 \mathrm{~min}$ at $37{ }^{\circ} \mathrm{C}$. The excess DCFH-DA was then discarded, and cells were washed with PBS. In the presence of ROS, DCFH was oxidized to highly fluorescent dichlorofluorescein (DCF), which was immediately measured using a microplate reader (Biotek, USA) at excitation and emission wavelengths of 485 and $530 \mathrm{~nm}$, respectively. The intracellular DCF fluorescence can be used as an index to quantify the overall ROS within treated cells compared with the control.

\section{Measurement of protein expression}

To determine the effects of $\mathrm{Cd}$ and rice extracts (WR, BR, GBR) on the expression of protein associated with antioxidant defense system (SOD2 and GPx4), after treatments, cells were lysed in RIPA buffer (Sigma-Aldrich, USA) including protease inhibitor cocktail (AMRESCO, USA \& Canada). Total protein concentrations were measured by BCA protein assay kit (Thermo Scientific, USA). $60 \mu \mathrm{g}$ of total protein was separated by SDS-PAGE and transferred onto $0.45 \mu \mathrm{m}$ PVDF membrane (Millipore, USA). The membranes were blocked with $5 \%$ non-fat dried milk (BIO BASIC, Canada) in TBST [Tris-buffered saline containing $0.1 \% \mathrm{v} / \mathrm{v}$ Tween 20 (AMRESCO, USA \& Canada)] for $1 \mathrm{~h}$; the membranes were then incubated overnight at $4{ }^{\circ} \mathrm{C}$ with specific primary antibodies: GPx4 (Boster Biological Technology, CA, USA), and SOD2 and $\beta$-actin (Cell Signaling Technology, USA). After that, horseradish peroxidase conjugated secondary antibodies (Millipore, USA) were incubated for $1 \mathrm{~h}$ at room temperature. Protein bands were visualized using enhanced chemiluminescence (Millipore, USA) and a chemiluminescence imager instrument (Image Quant LAS 500, GE Healthcare Life Sciences, Sweden). For quantification, the densities of each band were determined by Image J analysis software (National Institutes of Health (NIH), USA).

\section{Determination of antioxidant activity and total phenolic content}

To measure the antioxidant activity of WR, BR, and GBR extracts, 2,2-Diphenyl-1-picrylhydrazyl (DPPH) radical scavenging activity and total phenolic content were selected. Briefly, in a 96-well plate, $10 \mu \mathrm{l}$ of all rice samples were added to $140 \mu \mathrm{l}$ methanol solution of DPPH radical solution $(0.12 \mathrm{mM}$ final concentration). The mixture was mixed well and left in the dark at room temperature for $30 \mathrm{~min}$. Thereafter, the absorbance for the sample $\left(\mathrm{A}_{\text {sample }}\right)$ was measured using a microplate reader at $515 \mathrm{~nm}$, compared to methanol blank. A negative control $\left(\mathrm{A}_{\text {control }}\right)$ was $140 \mu \mathrm{l}$ of DPPH radical solution in the respective extraction solvent. The percent of DPPH scavenging activity of the sample was calculated by the equation:

$$
\left[\left(\underline{\mathrm{A}}_{\text {control }}-\mathrm{A}_{\text {sample }}\right) / \mathrm{A}_{\text {control }}\right] \times 100
$$

The free radical scavenging capacity of WR, BR, and GBR extracts was expressed as an equivalent of that of Trolox. The results were calculated and expressed as millimoles curves of Trolox equivalent antioxidant capacity (TEAC) per g of rice extracts using the standard of Trolox. The linearity range of the standard curve was 0.005 to $0.025 \mathrm{mM}(\mathrm{r}=0.99)$

The total phenolic content was examined by a Folin-Ciocalteu assay using gallic acid as the standard. The mixture of the reaction included sample solution $(10 \mu \mathrm{l})$ and distilled water $(215 \mu \mathrm{l})$, and 25 $\mu \mathrm{l}$ of Folin-Ciocalteu solution $(25 \mu \mathrm{l})$ was mixed and incubated for $30 \mathrm{~min}$ at room temperature. The absorbance was then measured at $765 \mathrm{~nm}$, using distilled water as a blank. The total phenolic content of the sample was calculated as the gallic acid equivalents (mg of GAE/g sample) by the standard curve of gallic acid. Linearity of the curve was 0.2 to $1 \mathrm{mg} / \mathrm{mL}(\mathrm{r}=0.99)$. 


\section{Statistics}

Data were expressed as the means \pm S.D. The comparison between groups was performed by ANOVA analysis and Tukey's HSD multiple comparisons. Differences of $p<0.05$ were considered to be statistically significant.

\section{Results and discussion}

In the present study, $\mathrm{Cd}$ induced high toxicity in JEG-3 cells, even at very low concentrations. As shown in Figure 1A, viability of JEG-3 cells was dramatically decreased and $50 \%$ of cell survival was shown at $0.9 \mu \mathrm{M} \mathrm{Cd}$ exposure $(\mathrm{IC} 50=0.9 \mu \mathrm{M})$. Meanwhile, cytotoxicity in all rice samples was not seen at concentrations $\leq 0.5 \mathrm{mg} / \mathrm{mL}$ (Figure 1B). The cytotoxic effect of $\mathrm{Cd}$ was presented by morphology changes (Figure 1C), including cell shape becoming round, dying cells beginning to detach, and the disappearance of nuclear structure [26].

(A)
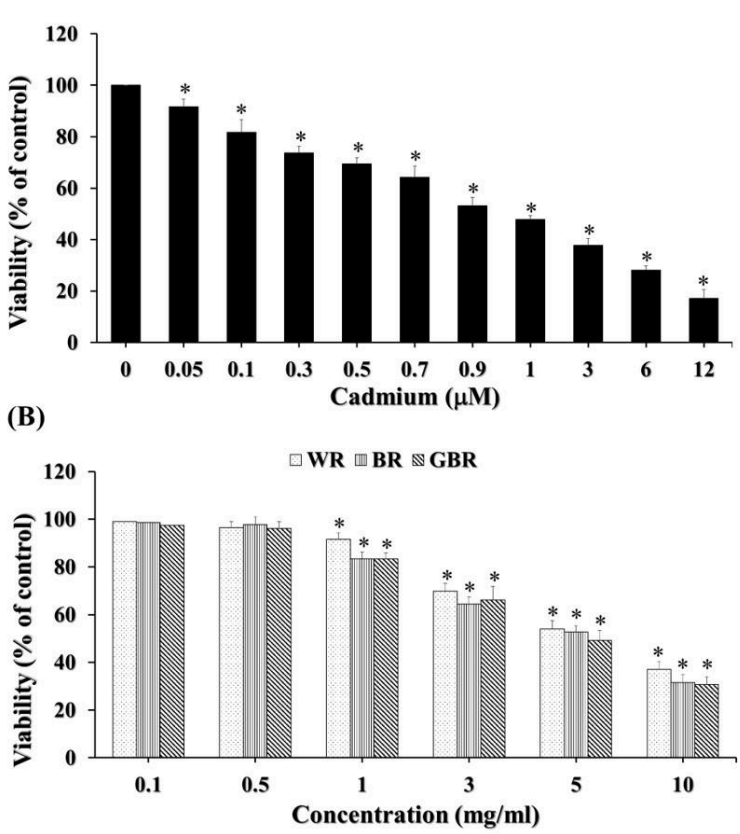

(C)

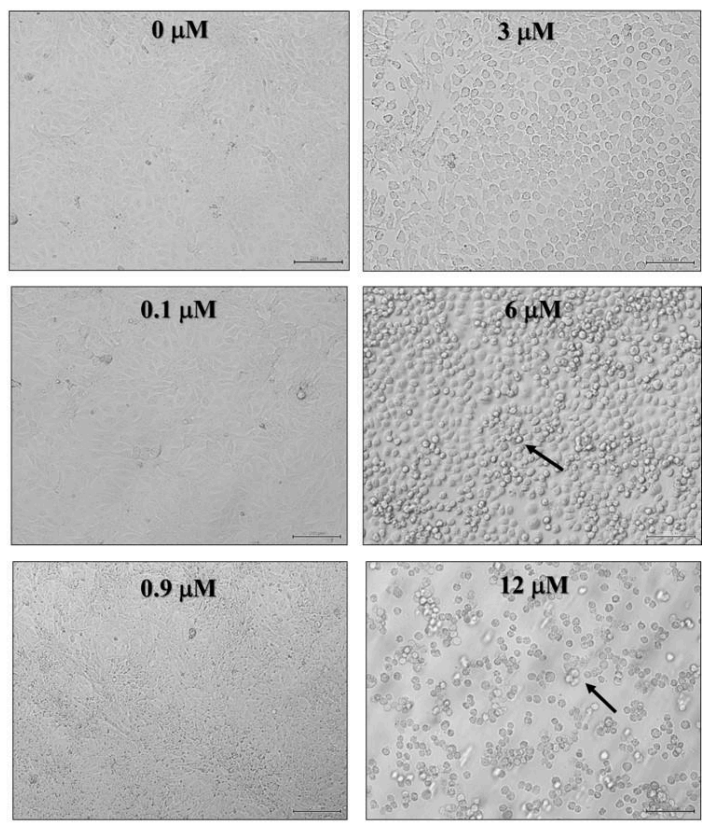

Figure 1 Viability of JEG-3 cells incubated for $24 \mathrm{~h}$ and $48 \mathrm{~h}$ with different concentrations of Cd (A) and rice extracts (WR, BR, GBR) (B), respectively. Cell morphology changes were shown after $24 \mathrm{~h} \mathrm{Cd}$ exposure $(\mathrm{C})$. Solid arrowhead in $(\mathrm{C})$ indicates round-shape and disappearance of nuclear structure. Results are the mean $\pm \mathrm{SD}$ of the absorbance expressed as the percentage related to control.

Previous studies revealed that $\mathrm{Cd}$, per se, is unable to generate ROS, but can do so through depletion of thiol status, such as glutathione and protein-bound sulfhydryl groups [27] and disturb the antioxidant defense system [28]. As a consequence, oxidative stress induced by Cd causes cell damage and cell death $[10,11,14,29,30]$. The toxic effect of Cd to placenta cells has been reported in human [31-33], animal [34], and cultured cell [24,35] models. These studies were concerned with the considerable results regarding placental structure and function for pregnancy complications, such as fetal growth restriction or development. Taken together, treatment or supplement with antioxidants may play a role to protect the cells from Cd toxicity. In the present study, pre-treatment with rice extract at a concentration of 0.5 $\mathrm{mg} / \mathrm{mL}$ was chosen to investigate its effect on ROS levels induced by Cd in cultured JEG-3 placenta cells. 
Table 1 Intracellular ROS levels of JEG-3 cells treated with various concentrations of Cd $(0.05-0.3 \mu \mathrm{M})$ and pre-treated with $0.5 \mathrm{mg} / \mathrm{mL}$ of GBR, BR, and WR extracts before exposure to $\mathrm{Cd}$.

\begin{tabular}{cccccc}
\hline & $\begin{array}{c}\text { ROS (\% of } \\
\text { control) } \\
\text { Cd-treated }\end{array}$ & $\begin{array}{c}\text { ROS (\% of } \\
\text { control) } \\
\mathbf{0 . 5} \mathbf{~ m g / m L} \\
\text { GBR pre-treated }\end{array}$ & $\begin{array}{c}\text { ROS (\% of } \\
\text { control) } \\
\mathbf{0 . 5} \mathbf{~ m g / m L} \\
\text { BR pre-treated }\end{array}$ & $\begin{array}{c}\text { ROS (\% of } \\
\text { control) } \\
\mathbf{0 . 5} \mathbf{~ m g / m L} \\
\text { WR pre-treated NAC pre-treated }\end{array}$ & $\begin{array}{c}\text { ROS (\% of } \\
\text { control) } \\
\mathbf{1 0} \mathbf{~ m M}\end{array}$ \\
\hline $\begin{array}{c}\text { Control } \\
\text { (untreated cells) }\end{array}$ & $100.00 \pm 0.00$ & $100.00 \pm 0.00$ & $100.00 \pm 0.00$ & $100.00 \pm 0.00$ & $100.00 \pm 0.00$ \\
$0.05 \mu \mathrm{M} \mathrm{Cd}$ & $99.92 \pm 4.89$ & $90.36 \pm 1.56^{* \#}$ & $91.59 \pm 3.72^{* \#}$ & $96.63 \pm 3.39$ & $89.08 \pm 4.27^{* \#}$ \\
$0.1 \mu \mathrm{M} \mathrm{Cd}$ & $102.61 \pm 5.41$ & $94.57 \pm 3.67^{*}$ & $95.72 \pm 4.82^{*}$ & $97.12 \pm 4.22$ & $92.06 \pm 2.85^{* \#}$ \\
$0.3 \mu \mathrm{M} \mathrm{Cd}$ & $110.63 \pm 5.38^{*}$ & $93.81 \pm 2.71^{*}$ & $100.34 \pm 3.67^{*}$ & $107.90 \pm 3.35$ & $93.11 \pm 7.77^{\#}$ \\
\hline
\end{tabular}

Results are the mean \pm SD of the absorbance expressed as the percentage related to control. $*=p<0.05$ compared to control; \# $=p<0.05$ compared to Cd-treated group.

As shown in Table 1, ROS levels significantly increased $(p<0.05)$ in JEG-3 cells exposed to various concentrations of $\mathrm{Cd}$ in a dose-dependent manner, whereas those pre-treated with the rice extracts decreased their levels in JEG-3 cells after exposure to Cd. The GBR $(90.36 \% \pm 1.56)$ showed the most efficiency to reduce ROS levels at a concentration of $0.5 \mathrm{mg} / \mathrm{mL}$, followed by BR $(91.59 \% \pm 3.72)$ and WR $(96.63 \% \pm 3.39)$ extracts, compared to untreated cells. As a positive control, an antioxidant NAC decreased ROS levels by $26 \%(89.08 \% \pm 4.27)$.

For pre-treatments with rice extracts, it was indicated that pre-treatment with $0.5 \mathrm{mg} / \mathrm{mL}$ of GBR and BR (Table 1) for $48 \mathrm{~h}$ before exposure to $0.05-0.3 \mu \mathrm{M} \mathrm{Cd}$ was more efficient in decreasing ROS levels than WR when compared with the low concentration of $\mathrm{Cd}(0.05 \mu \mathrm{M})$ treated group. Nevertheless, the protective effect of rice pre-treatments were not presented at high concentrations of $\mathrm{Cd}(\geq 0.1 \mu \mathrm{M})$ exposure. However, positive control NAC pre-treatments effectively decreased ROS levels in all Cdtreated groups. This revealed that pre-treatment with antioxidants can influence antioxidative status in JEG-3 cells induced by $\mathrm{Cd}$, as reflected by lowering ROS.

Brown rice has more nutritional components than white rice, which mainly come from the outer layer of rice grains or rice bran and are lost during polishing [36]. These components include $\gamma$ aminobutyric acid (GABA), dietary fiber, phytic acid, tocotrienols, and gamma-oryzanol, and these components may be enhanced in germinated brown rice during the germination process [36,37]. Their biological activities are useful for health effects such as lowering blood pressure, preventing heart disease, and preventing colon cancer [18]. Recent studies reported that rice bran extract could be an effective antioxidant due to its action on free radical-scavenging, reducing capacity, metal ion-chelation, and inhibition of lipid peroxidation [38,39]. Our recent study demonstrated that the levels of GABA and gamma-oryzanol were higher in GBR than BR [40]. In this study, antioxidant activity and total phenolic content in all rice samples were examined. The results demonstrated that GBR had the greatest radical scavenging activity and phenolic contents, followed by BR and WR, respectively. These were in agreement with a previous study [37] which reported that WR had significantly lower levels of phenolics than BR and GBR.

It has been shown that two of the major phenolics found in WR, BR, and GBR were ferulic acid and $p$-coumaric acid, with them being most abundant in GBR [37]. Ferulic acid, which is ester linked to sterol as part of $\gamma$-oryzanol and bound to insoluble fiber forming the cell walls, exhibits antioxidant activity in response to free radicals [41]. In addition, its scavenging activity is found to be similar to that of superoxide dismutase [41-43]. GABA is also a bioactive compound found in whole rice grains and is 
highly produced during the grain germination process [24]. Its effect on antioxidative status has been reported [44]. GABA can improve antioxidation status in pigs by increasing the activities of serum GPx, SOD, catalase (CAT), and decreasing malondialdehyde (MDA), a product of lipid peroxidation, levels during heat stress [45].

In the present study, the antioxidant activities of WR, BR, and GBR extracts were determined by DPPH assay. The activity was expressed as TEAC/g rice extracts and NAC was used as a standard antioxidant. As shown in Figure 2, the scavenging DPPH activity by standard Trolox and antioxidant NAC increased with increasing concentrations (Figure 2). From the results, Trolox exhibited the highest scavenging activity, followed by NAC and rice extracts. For rice samples, the DPPH activity was significantly influenced $(p<0.05)$ by type of rice. GBR extract revealed the highest DPPH activity, followed by BR and WR extracts. The DPPH activity of 3 different rice extracts ranged from 2.99 to $78.69 \%$, whereas Trolox and NAC were from 15.11 to $93.33 \%$ and 13.55 to $85.29 \%$, respectively. The IC50 values of WR, BR, and GBR extracts against DPPH activity were 10.31, 7.40, and $5.31 \mathrm{mg} / \mathrm{mL}$, respectively, and that of Trolox and NAC were 3.43 and $5.88 \mathrm{mg} / \mathrm{mL}$, respectively (Table 1). For rice samples, the lowest IC50 value was obtained in GBR, indicating that GBR exhibited potent antioxidant capacity compared to that of BR and WR, whereas for standard antioxidant, Trolox had more antioxidant capacity than NAC. While expressed as TEAC, the DPPH value of $0.5 \mathrm{mg} / \mathrm{mL}$ of WR, BR, and GBR extracts was 541.33, 865.13, and 1261.66 mmoles TEAC/g of rice extract, respectively. Further, it was found that GBR exhibited the highest amount of total phenolic content (1102.11 mg GAE/g), followed by BR (794.85 mg GAE/g) and WR (470.46 mg GAE/g), respectively (Table 2).

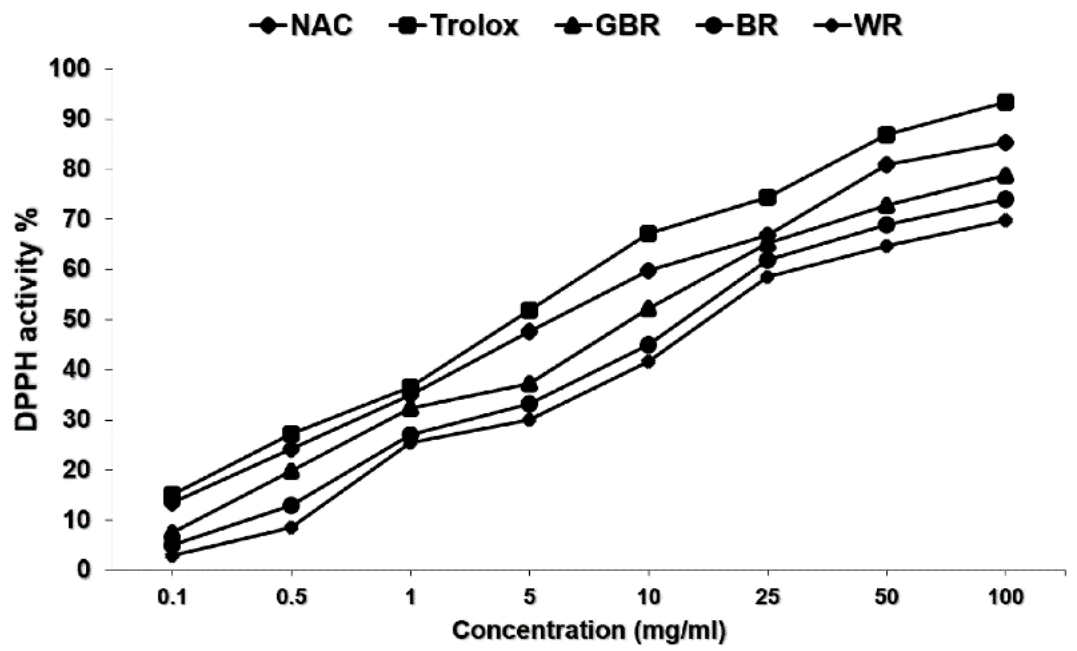

Figure 2 DPPH radical scavenging activity of rice extracts (WR, BR, and GBR), Trolox, and NAC. 
Table 2 Total phenolic content of white rice (WR), brown rice (BR), and germinated brown rice (GBR) extracts by Folin-Ciocalteu assay.

\begin{tabular}{ccc}
\hline Type of rice & $\begin{array}{c}\text { Total phenolic content } \\
\text { (mg GAE/g of rice extract) }\end{array}$ & $\begin{array}{c}\text { DPPH free radical activity IC50 values } \\
(\mathbf{m g} / \mathbf{m L})\end{array}$ \\
\hline WR & $470.46 \pm 22.87$ & 10.31 \\
BR & $794.85 \pm 102.35$ & 7.40 \\
GBR & $1102.11 \pm 43.02$ & 5.31 \\
Trolox & NA & 3.43 \\
NAC & NA & 5.89 \\
\hline
\end{tabular}

NA $=$ Not available

In addition, in this study, antioxidant protein (SOD2 and GPx4) expression was measured to investigate whether GBR, BR, or WR extract have a protective effect on antioxidant defense system in JEG-3 cells induced by $\mathrm{Cd}$. The results were expressed as relative expressions of SOD2 (Figure 3) and GPx4 (Figure 4) proteins to $\beta$-actin.

For rice treatment groups, it was indicated that $48 \mathrm{~h}$ treatment with GBR significantly up-regulated $(p<0.05)$ both SOD2 (Figure 3) and GPx4 (Figure 4) expression much higher than BR and WR treated groups, respectively, compared with the control. Meanwhile, for $24 \mathrm{~h}$ incubation with $0.3 \mu \mathrm{M} \mathrm{Cd}$, SOD2 and GPx4 expression were significantly increased $(p<0.05)$.

Moreover, the results indicated that after $48 \mathrm{~h}$ pre-treatment with $0.5 \mathrm{mg} / \mathrm{mL} \mathrm{GBR,} \mathrm{BR,} \mathrm{and} \mathrm{WR}$ followed by $0.05 \mu \mathrm{M}$ Cd treated group, GPx4 protein expression was significantly $(p<0.05)$ decreased compared with the non-pre-treated group (Figure 4), whereas SOD2 expression was up-regulated only in the GBR pre-treated group (Figure 3).

In addition, pre-treatment with BR and WR had no effect on SOD2 expression compared with the Cd-treated group. However, BR showed higher efficiency to scavenge intracellular ROS in JEG-3 cells exposed to Cd than WR (Table 1). This suggests that pre-treatment with GBR may reveal the protective defenses and are proposed to act as the first line to scavenge free radicals induced by Cd. However, at high concentrations of $\mathrm{Cd}$ exposure, GBR extract had slight influence on the antioxidant defense system, signifying that $\mathrm{Cd}$ is a potent heavy metal ion harmful to the cells. To our knowledge, this study is the first in vitro report of the protective effects of GBR and BR on human placental cell lines. However, the role of these rice extracts involved in defense mechanisms during $\mathrm{Cd}$ stress still needs to be clarified further, such as the measurement of antioxidant enzyme activities.

In addition, pre-treatment with $10 \mathrm{mM}$ NAC down-regulated GPx4 expression in cells exposed to $0.3 \mu \mathrm{M} \mathrm{Cd}$ compared with Cd treated group (Figure 4). However, expression of SOD2 was unchanged in all NAC pre-treatments (Figure 3). In agreement with rice pre-treatments, these results suggest that supplementation of antioxidants may protect JEG-3 cells from Cd toxicity. 
(A)

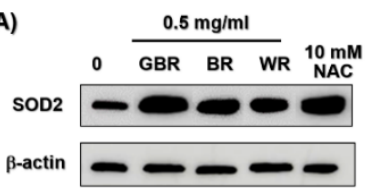

(B)

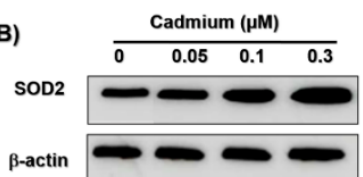

(C)
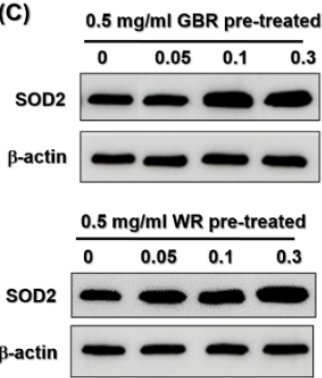

SOD2
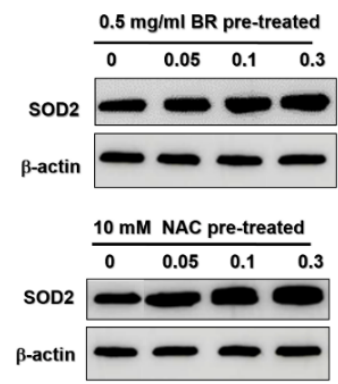

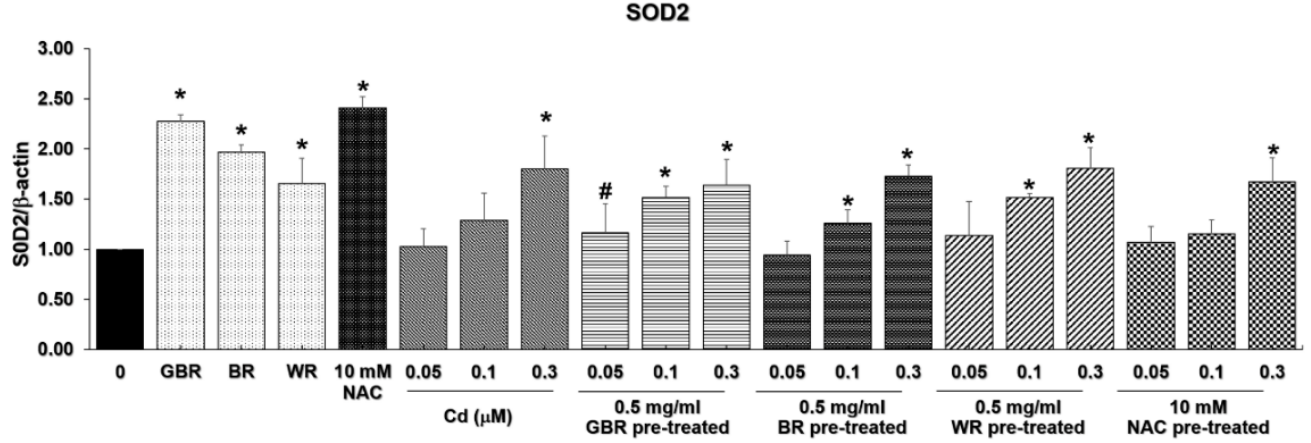

Figure 3 SOD2 protein expression of JEG-3 cells treated with (A) rice extracts (GBR, BR, WR), (B) Cd, and (C) $48 \mathrm{~h}$ pre-treated with different concentrations of WR, BR, GBR extracts and NAC before $24 \mathrm{~h} \mathrm{Cd}$ exposure. Results are the mean $\pm \mathrm{SD} .{ }^{*}=p<0.05$ compared to control; $\#=p<0.05$ compared to $\mathrm{Cd}$ treated group.

(A)

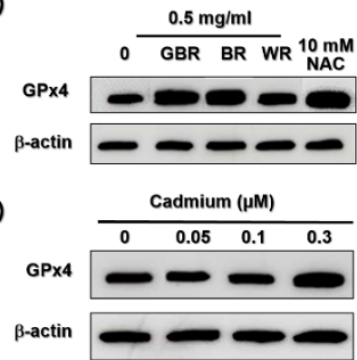

(C)

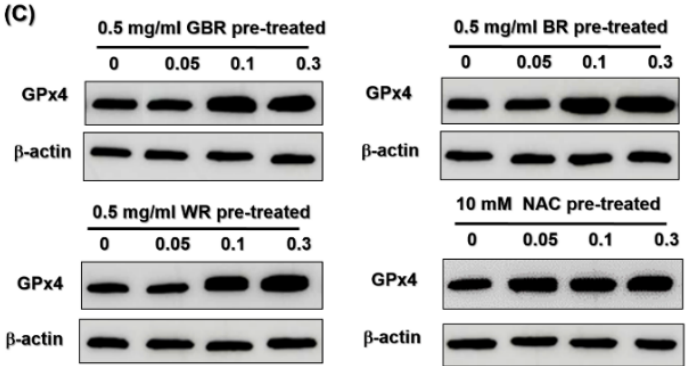

GPx4

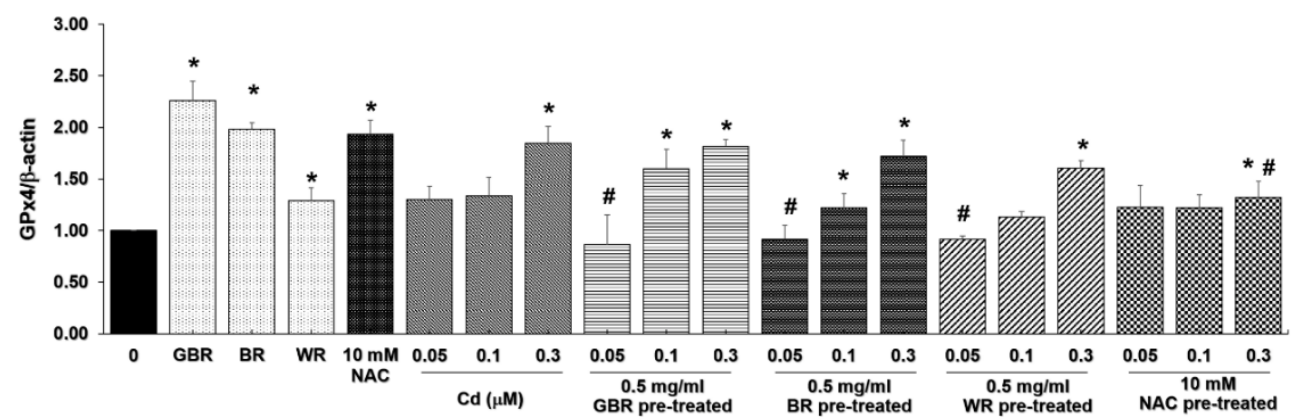

Figure 4 GPx4 protein expression of JEG-3 cells treated with (A) rice extracts, (B) Cd, and (C) 48 h pretreated with different concentrations of GBR, BR, WR extracts and NAC before $24 \mathrm{~h} \mathrm{Cd}$ exposure. Results are the mean $\pm \mathrm{SD}$. $*=p<0.05$ compared to control; $\#=p<0.05$ compared to Cd treated group. 
However, at higher concentrations of Cd exposure $(0.1-0.3 \mu \mathrm{M})$, the expression level of SOD2 in all rice pre-treatments was also increased, but not significantly compared to Cd-treated groups. This suggested that a concentration of $0.5 \mathrm{mg} / \mathrm{mL}$ of rice extracts may not able to lessen Cd toxicity. Nevertheless, interestingly, GPx4 protein expression was significantly decreased $(p<0.05)$ in all rice pretreatments in cells exposed to $0.05 \mu \mathrm{M}$ Cd (Figure 4). This may be due to their role and the level of antioxidant actions in relation to SOD2 [46].

In addition, the present study also demonstrated the association between $\mathrm{Cd}$ and oxidative stress in JEG-3 cells. From Pearson correlation analysis, the negative correlation $(\mathrm{r}=-0.727, p<0.01)$ demonstrated that high ROS levels in JEG-3 cells induced by Cd $(0-0.5 \mu \mathrm{M})$ dramatically decreased cell viability (Figure 5A). In addition, the antioxidant defense response in oxidative stress induced by $\mathrm{Cd}$ was shown by up-regulating the expression of antioxidant proteins SOD2 and GPx4, as indicated in Figure 5B. The results (Figure 5B) showed the positive correlation between ROS levels and expression of SOD2 $(\mathrm{r}=0.672, p<0.0 .5)$ and GPx4 proteins $(\mathrm{r}=0.865, p<0.01)$.

(A)

(B)
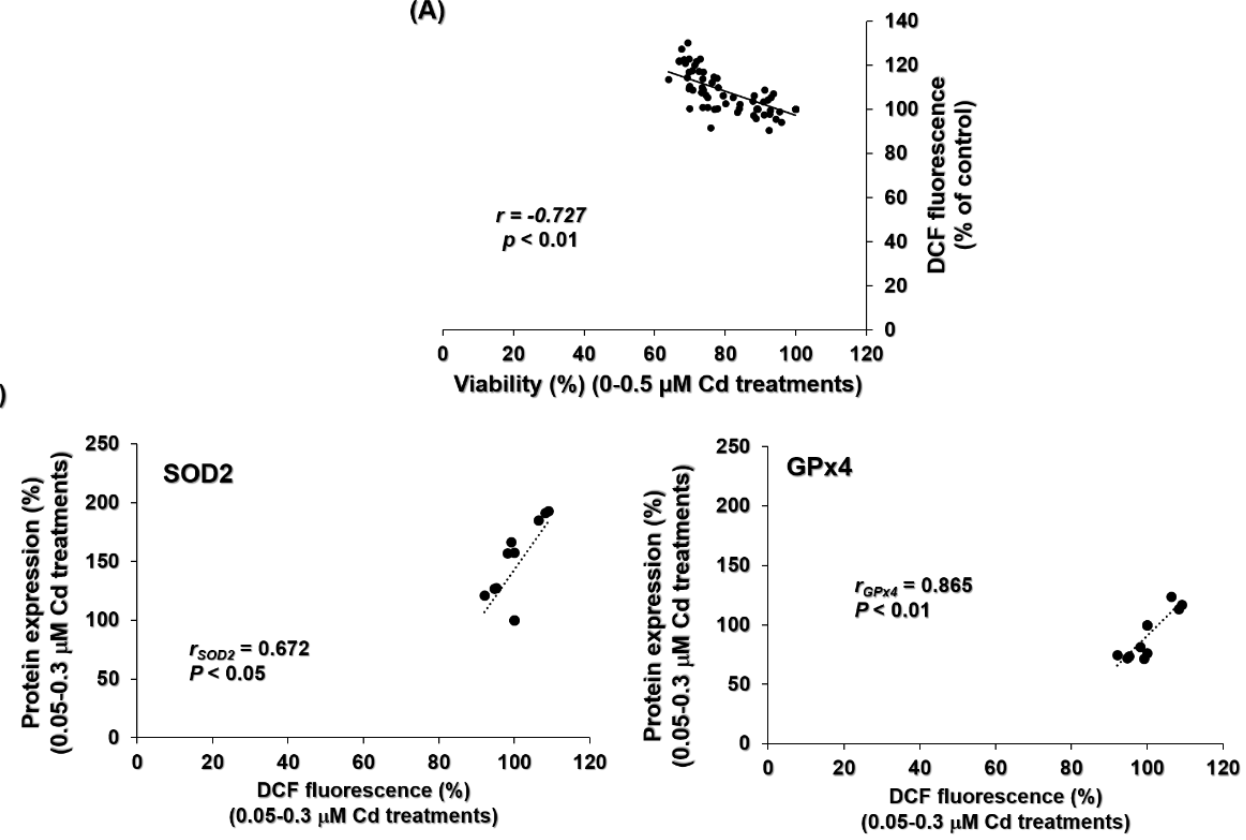

Figure 5 The Pearson correlation analysis between (A) viability and ROS levels in JEG-3 cells treated with $0-0.5 \mu \mathrm{M} \mathrm{Cd}$ and (B) SOD2 and GPx4 protein expression and ROS levels in JEG-3 cells treated with $0-0.5-0.3 \mu \mathrm{M} \mathrm{Cd}$.

Moreover, it also demonstrated that GPx4 (Figure 6A) and SOD2 (Figure 6B) expression were negatively correlated with ROS levels in GBR (SOD2, $\mathrm{r}=-0.745, p<0.01$; GPx4, $\mathrm{r}=-0.814, p<0.01$ ) and BR (SOD2, $\mathrm{r}=-0.817, p<0.01$; GPx4, $\mathrm{r}=-0.651, p<0.05$ ) pre-treatment groups after exposure to low concentration $\mathrm{Cd}(0.05 \mu \mathrm{M})$. These results indicated that GBR and BR extracts may affect the cellular defense mechanism to reduce Cd toxicity. However, such a correlation was not seen in WR pretreatments.

Taken together, these results demonstrated that $\mathrm{Cd}$ treatment perturb cellular oxidative status and that pre-treatments with GBR and BR that have antioxidant activity may help to protect cells from Cdinduced oxidative stress through the reduction of ROS and regulation of antioxidant SOD2 and GPx4 protein expression. 
(A)
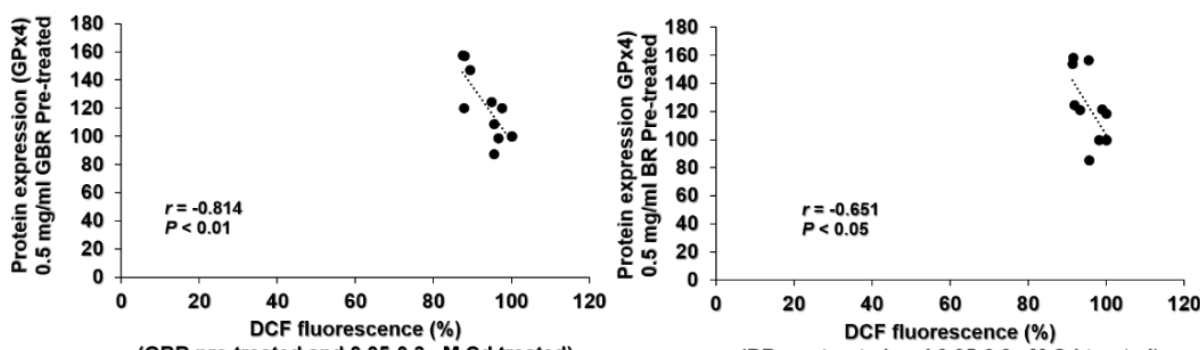

(B)
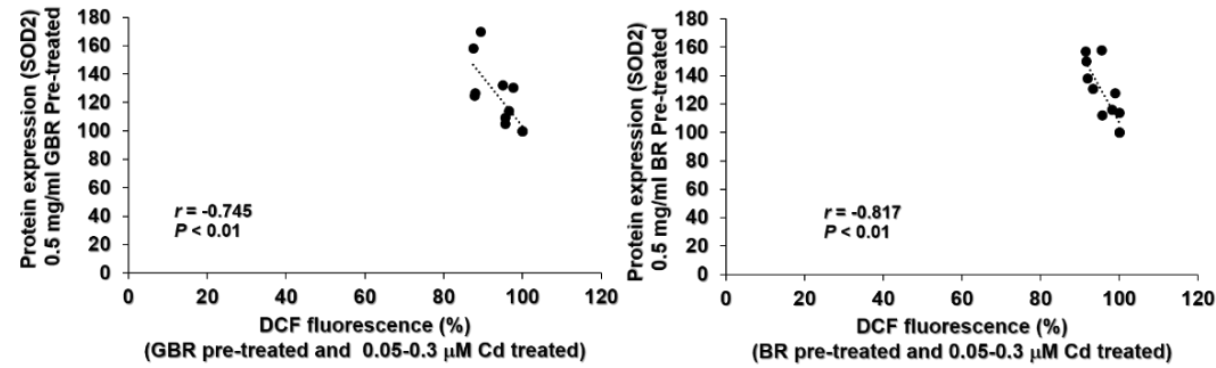

Figure 6 Pearson correlation analysis between (A) GPx4, (B) SOD2 protein expression and ROS levels in JEG-3 cells pre-treated with GBR and BR $(0.5 \mathrm{mg} / \mathrm{mL})$ before Cd treatments $(0.05-0.3 \mu \mathrm{M})$.

\section{Conclusions}

The present study demonstrated that cultured JEG-3 cells, a model for the human placental trophoblast, exposed to $\mathrm{Cd}$ increased intracellular ROS levels and induced antioxidant defense response through up-regulation of the expression of antioxidant enzymes SOD2 and GPx4. Nevertheless, cells supplemented with BR and GBR extracts protected cells from Cd toxicity, as reflected by decreasing ROS. By improving oxidative status, BR and GBR affected the antioxidant defense systems within the cells by acting on the basis of line of antioxidant defense through up-regulating SOD2 and downregulating GPx4 production.

This study presented preliminary results suggesting that pregnant women should avoid exposure to a state of oxidative stress induced by the toxic metal ion $\mathrm{Cd}$ and that supplementation by antioxidants may help to protect cells and will not affect pregnancy outcome [3,9,46,47]. Moreover, further studies may need to verify other important mechanisms involved in the beneficial effects of BR and GBR against Cd toxic effects.

\section{Acknowledgements}

This work was supported by a grant from the National Research Council of Thailand (R2560B130). We are thankful to Dr. Warunee Dansithong, University of Utah, for manuscript proofreading and editing.

\section{References}

[1] L Järup and A Akesson. Current status of cadmium as an environmental health problem. Toxicol. Appl. Pharmacol. 2009; 238, 201-8.

[2] RK Zalups and S Ahmad. Molecular handling of cadmium in transporting epithelia. Toxicol. Appl. Pharmacol. 2003; 186, 163-88.

[3] J Godt, F Scheidig, C Grosse-Siestrup, V Esche, P Brandenburg, A Reich and DA Groneberg. The toxicity of cadmium and resulting hazards to human health. J.Occup. Med. Toxic. 2006; 1, 22. 
[4] A Sarkar, G Ravindran and VA Krishnamurthy. Brief review on the effect of cadmium toxicity: From cellular to organ level. Int. J. Biotechnol. Res. 2013; 3, 17-36.

[5] RM Rafati, RM Rafati, S Kazemi and AA Moghadamnia. Cadmium toxicity and treatment: An update. Caspian J. Intern. Med. 2017; 8, 135-45.

[6] A El-Sayed, MS Salem, AE Amany, AR Zeinab and MK Asmaa. Protective effect of zinc against cadmium toxicity on pregnant rats and their fetuses at morphological, physiological and molecular level. Afr. J. Biotechnol. 2013; 12, 2110-9.

[7] GB Zhang, H Wang, J Hu, MY Guo, Y Wang, Y Zhou, Z Yu, L Fu, YH Chen and DX Xu. Cadmium-induced neural tube defects and fetal growth restriction: Association with disturbance of placental folate transport. Toxicol. Appl. Pharmacol.2016; 306, 79-85.

[8] C Dechanet, T Anahory, JC Mathieu Daude, X Quantin, L Reyftmann, S Hamamah, B Hedon and H Dechaud. Effects of cigarette smoking on reproduction. Hum. Reprod. Update. 2011; 17, 76-95.

[9] Saad AA, Hegazy NM, Amer N, Gaber K, Youssef AI, Sharaf NE and NAM Diab. The role of cadmium exposure on spontaneous abortion. World J. Med. Sci. 2012; 7, 270-5.

[10] Cuypers A, Plusquin M, Remans T, Jozefczak M, Keunen E, Gielen H, K Opdenakker, AR Nair, E Munters, TJ Artois, T Nawrot, J Vangronsveld and K Smeets. Cadmium stress: An oxidative challenge. Biometals 2010; 23, 927-40.

[11] JB Samuel, J Stanley, RA Princess, P Shanthi and MS Sebastian. Gestational cadmium exposureinduced ovotoxicity delays puberty through oxidative stress and impaired steroid hormone levels. $J$. Med. Toxicol. 2011; 7, 195-204.

[12] K Jomova and M Valko. Advances in metal-induced oxidative stress and human disease. Toxicology $2011 ; 283,65-87$.

[13] SJ Flora. Structural, chemical and biological aspects of antioxidants for strategies against metal and metalloid exposure. Oxid. Med. Cell. Longev. 2009; 2, 191-206.

[14] M Kanter, B Aksu, M Akpolat, YT Tarladacalisir, C Aktas and H Uysal. Vitamin E protects against oxidative damage caused by cadmium in the blood of rats. Eur. J. Gen. Med. 2009; 6, 154-60.

[15] HM Abdou, NA Mohamed, DAE Mekkawy and SB EL-Hengary. Vitamin E and/or wheat germ oil supplementation ameliorate oxidative stress induced by cadmium chloride in pregnant rats and their fetuses. Jordan J. Biol. Sci. 2017; 10,39-48.

[16] RR Devi and C Arumughan. Phytochemical characterization of defatted rice bran and optimization of a process for their extraction and enrichment. Biores. Technol. 2007; 98, 3037-43.

[17] MJ Lerma-Garcia, JM Herrero-Martinez, EF Simo-Alfonso, CRB Mendonca and G Ramis-Ramos. Composition, industrial processing and applications of rice bran gamma-oryzanol. Food Chem. 2009; 115, 389-404.

[18] SB Patil and K Khan. Germinated brown rice as a value added rice product: A review. J. Food Sci. Technol. 2011; 48, 661-7.

[19] MJ Son, CW Rico, SH Nam and MY Kang. Influence of oryzanol and ferulic acid on the lipid metabolism and antioxidative status in high fat-fed mice. J. Clin. Biochem. Nutr. 2010; 46, 150-6.

[20] MS Islam, T Murata, M Fujisawa, R Nagasaka, H Ushio, AM Bari, M Hori and H Ozaki. Antiinflammatory effects of phytosteryl ferulates in colitis induced by dextran sulphate sodium in mice. Br. J. Pharmacol. 2008; 154, 812-24.

[21] BL Tan and ME Norhaizan.Scientific evidence of rice by-products for cancer prevention: chemopreventive properties of waste products from rice milling on carcinogenesis in vitro and in vivo. BioMed Res. Int. 2017; 2017, 1-18.

[22] MJ Son, CW Rico, SH Nam and MY Kang. Effect of oryzanol and ferulic acid on the glucose metabolism of mice fed with a high-fat diet. J. Food Sci. 2011; 76, H7-H10.

[23] IO Minatel, FV Francisqueti, CR Corrêa, and GPP Lima. Antioxidant activity of $\gamma$-oryzanol: A complex network of interactions. Int. J. Mol. Sci. 2016; 17, 1107.

[24] SB Patil and K Khan. Germinated brown rice as a value added rice product: A review. J. Food Sci. Technol. 2011; 48, 661-7. 
[25] JN Ho, ME Son, WC Lim, ST Lim and HY Cho. Germinated brown rice extract inhibits adipogenesis through the down-regulation of adipogenic genes in 3T3-L1 adipocytes. Plant Foods Hum. Nutr. 2013; 68, 274-8.

[26] FJ Lin, JW Fitzpatrick, CA lannotti, DS Martin, BD Mariani and RS Tuan. Effects of Cadmium on Trophoblast Calcium Transport. Placenta 1997; 18, 341-56.

[27] SJ Stohs, D Bagchi, E Hassoun and M Bagchi. Oxidative mechanisms in the toxicity of chromium and cadmium ions. J. Environ. Pathol. Toxicol. Oncol. 2001; 202, 77-88.

[28] N Ercal, H Gurer-Orhan and N Aykin-Burns. Toxic metals and oxidative stress part I: Mechanisms involved in metal-induced oxidative damage. Curr. Top. Med. Chem. 2001; 1, 529-39.

[29] U Kukongviriyapan, K Apaijit and V Kukongviriyapan. Oxidative stress and cardiovascular dysfunction associated with cadmium exposure: Beneficial effects of curcumin and tetrahydrocurcumin. Tohoku J. Exp. Med. 2016; 239, 25-38.

[30] I Al-Saleh, N Shinwari, A Mashhour, GElD Mohamed and A Rabah. Heavy metals (lead, cadmium and mercury) in maternal, cord blood and placenta of healthy women. Int. J. Hyg. Environ. Health. $2011 ; 214,79-101$.

[31] M Kippler, AM Hoque, R Raqib, H Öhrvik, EC Ekström and M Vahter. Accumulation of cadmium in human placenta interacts with the transport of micronutrients to the fetus. Toxicol. Lett. 2010; 192, 162-8.

[32] AM Ronco, G Arguello, L Munoz, N Gras and M Llanos. Metals content in placentas from moderate cigarette consumers: Correlation with newborn birth weight. Biometals 2005; 18, 233-41.

[33] S Stasenko, EM Bradford, M Piasek, MC Henson, VM Varnai, J Jurasovic and V Kusec. Metals in human placenta: focus on the effects of cadmium on steroid hormones and leptin. J. Appl. Toxicol. 2010; 30, 242-53.

[34] M Erboga and M Kanter. Effect of cadmium on trophoblast cell proliferation and apoptosis in different gestation periods of rat placenta. Biol. Trace Elem. Res. 2016; 169, 285-93.

[35] AM Ronco, E Llaguno, MJ Epuñan and MN Llanos. Effect of cadmium on cortisol production and 11b-hydroxysteroid dehydrogenase 2 expression by cultured human choriocarcinoma cells (JEG-3). Toxicol. In Vitro. 2010; 24, 1532-7.

[36] J Banchuen, P Thammarutwasik, B Ooraikul, P Wuttijumnong and P Sirivongpaisal. Effect of germinating processes on bioactive component of sangyodmuangphatthalung rice. Thai J. Agric. Sci. 2009; 42, 191-9.

[37] S Tian, K Nakamura and H Kayahara. Analysis of phenolic compounds in white rice, brown rice, and germinated brown rice. J. Agric. Food Chem. 2004; 52, 4808-13.

[38] A Ghasemzadeh, HZ Jaafar, AS Juraimi and A Tayebi-Meigooni. Comparative evaluation of diferent extraction techniques and solvents for the assay of phytochemicals and antioxidant activity of Hashemi rice bran. Molecules 2015; 20, 10822-38.

[39] IM Sani, S Iqbal, KW Chan and M Ismail. Effect of acid and base catalyzed hydrolysis on the yield of phenolics and antioxidant activity of extracts from germinated brown rice (GBR). Molecules 2012; 17, 7584-94.

[40] W Bulanawichit, $\mathrm{T}$ Kirdin and $\mathrm{T}$ Boonsong. Effects of brown rice and germinated brown rice extracts from Thai rice cultivars (PL2 and KDML105) on adipogenic, adipocytokine, and antioxidant genes in 3T3-L1 adipocytes. Chiang Mai Univ. J. Nat. Sci. 2018; 17, 79-96.

[41] M Patel and SN Naik. Gamma-oryzanol from rice bran oil: A review. J. Sci. Ind. Res. 2004; 63, 56978.

[42] H Kikuzaki, M Hisamoto, K Hirose, K Akiyama and H Taniguchi. Antioxidant properties of ferulic acid and its related compounds. J. Agric. Food Chem. 2002; 50, 2161-9.

[43] S Itagaki, T Kurokawa, C Nakata, Y Saito, S Oikawa, M Kobayashi, T Hirano and K Iseki. In vitro and in vivo antioxidant properties of ferulic acid: A comparative study with other natural oxidation inhibitors. Food Chem. 2009; 114, 466-71.

[44] JC Hu, XT Zou and DR Cao. Effect of gamma-aminobutyric acid on serum biochemical parameter of finishing hogs in summer. LiaoNing (P.R.China). Feed Ind. 2008; 29, 9-11. 
[45] OM Ighodaro and OA Akinloye. First line defence antioxidants-superoxide dismutase (SOD), catalase (CAT) and glutathione peroxidase (GPX): Their fundamental role in the entire antioxidant defence grid. Alexandria J. Med. 2018; 54, 287-93.

[46] L Järup, M Berglund, CG Elinder, G Nordberg abd M Vahter. Health effects of cadmium exposurea review of the literature and a risk estimate. Scand. J. Work Environ. Health 1998; 24, 1-5.

[47] YL Zhang, YC Zhao, JX Wang, HD Zhu, QF Liu, YG Fan, NF Wang, JH Zhao, HS Liu, L OuYang, AP Liu and TQ Fan. Effect of environmental exposure to cadmium on pregnancy outcome and fetal growth: a study on healthy pregnant women in China. J. Environ. Sci. Health A Tox. Hazard Subst. Environ. Eng. 2004; 39, 2507-15. 